\title{
What is the future of animal biotechnology?
}

\author{
by Alison L. Van Eenennaam
}

Animal biotechnology encompasses a broad range of techniques for the genetic improvement of domesticated animal species, although the term is increasingly associated with the more controversial technologies of cloning and genetic engineering. Despite the many potential applications of these two biotechnologies, no public or private entity has yet delivered a genetically engineered food-animal product to the global market, and the sale of milk or meat from cloned animals and their offspring is currently subject to a voluntary moratorium in the United States. The animal biotechnology industry faces a variety of scientific, regulatory, ethical and public acceptance issues. Effective and responsible communication among scientific, community, industry and government stakeholders will be required to reach a societal consensus on the acceptable uses of animal cloning and genetic engineering.

A Varticle published in California engineering and cloning may improve milk, livestock production" (Murray and Anderson 2000) detailed potential uses of these biotechnologies and optimistically concluded that "by midcentury most agricultural animals will be genetically engineered to be more efficient and healthier than current stock, producing healthy products for human consumption in an environmentally friendly system." While these technologies undoubtedly have the potential to deliver such benefits, no genetically engineered food animals are currently on the market, and the U.S. Food and Drug Administration (FDA) continues to call for a voluntary prohibition on the marketing of milk or meat from clones and their offspring. This review examines the

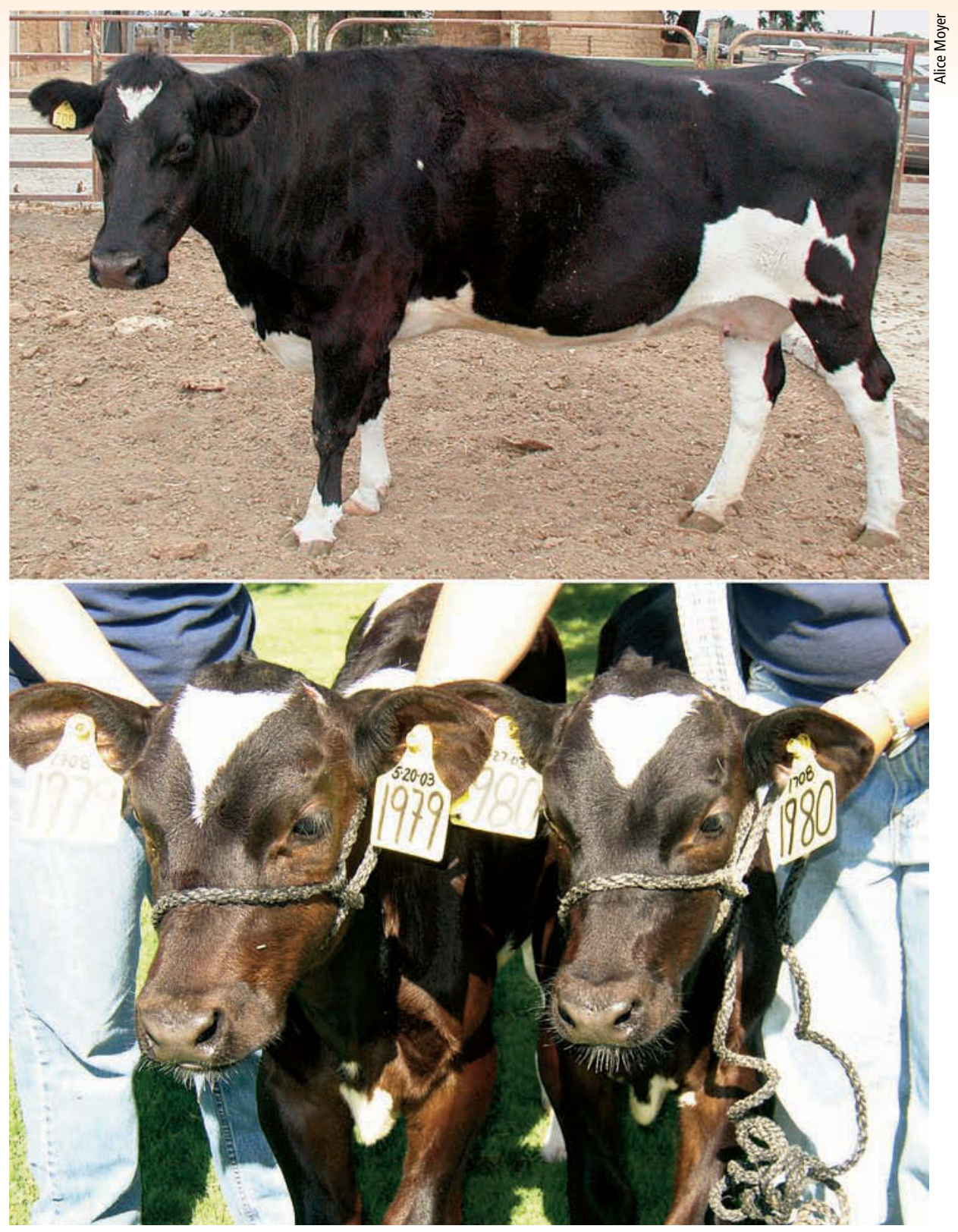

Above left, Dot was cloned by UC Davis scientists from granulosa cells and, above right, Ditto from cumulus cells (both ovarian, follicular cell types) derived from, top, Daisy. Dot and Ditto were born in May 2003 and are normal, healthy cows. Both of the cloned cows have had calves, which also appear to be normal.

scientific, regulatory, ethical and public acceptance issues faced by the animal biotechnology industry, and discusses the implications of the current climate on the future of animal biotechnology.

Biotechnology is defined as technology based on biology. From this definition it is obvious that livestock breeders have been practicing animal biotechnology for many years. For example, traditional selection techniques involve using observations about the physical attributes and biological characteristics of an animal to select the parents of the next generation. One needs only to look at the amazing variety of dog breeds to realize the influence that breeders can have on the appearance and characteristics of animals from a single species. Genetic improvement through selection, based on an increased understanding of population genetics and statistics, has 


\section{GLOSSARY}

been an important contributor to dramatic advances in agricultural productivity (Dekkers and Hospital 2002).

Many different biotechnologies have been incorporated into livestock breeding programs to accelerate the rate of genetic improvement. These include artificial insemination (AI), sire-testing programs using data collected from thousands of offspring, synchronization of estrus, embryo transfer, cryopreservation of gametes and embryos, and DNA-based marker-assisted selection of genetically superior animals. Prior to their eventual widespread adoption, some of these new technologies were controversial, and their introduction met with some resistance (NRC 2002). Initially, artificial insemination was seen to be "against the laws of God, a repugnant practice that would lead to abnormal outcomes" (NRC 2002). Today this technology is widely used in agriculture, in addition to both veterinary and human medicine. Genetic improvements using traditional breeding techniques have not come without a price, and there are some health and welfare concerns associated with highly productive animals, such as gait abnormalities in broiler chickens and fertility problems in high-yielding dairy cattle. A comparable legacy has arisen from the selective breeding of domesticated dogs, which are now afflicted with more than 200 diseases of genetic origin.

\section{Animal cloning}

When most people hear the term animal biotechnology, they think of Dolly the sheep, the first mammal ever cloned or duplicated from an adult cell. The hype that surrounded Dolly in 1997 rapidly became entangled with the debate over human cloning, and the ensuing discussion failed to elaborate on the reasons for, or even differentiate between, cloning versus the genetic engineering of animals.

Cloning had actually been practiced for a long time before the appearance of Dolly. Splitting or bisecting embryos to make identical twins, a process in which the cells of a developing embryo are split in half and transferred into different recipient mothers, was introduced into livestock breeding programs in the 1980s. Identical twins are technically
Chromosome: A self-replicating DNA sequence found in the cell nucleus that bears a linear array of genes.

Cytoplasm: The cellular substance outside the nucleus in which the cell's organelles, such as mitochondria, are suspended.

Genetic engineering: The transfer of recombinant DNA sequences into the genome of a living organism.

Genome: The total DNA in a single cell, representing all of the genetic information of the organism. The normal human genome consists of 46 chromosomes, 23 from each parent.

Mitochondria: Components in cells that serve as primary energy sources for all cellular functions. Mitochondria have their own genome, present in only one copy, which does not recombine in reproduction.

Nucleus: A separate compartment in the cell that contains 6 feet of DNA packed into 23 pairs of chromosomes.

Recombinant DNA: The laboratory manipulation of DNA in which DNA, or fragments of DNA from different sources, are cut and recombined using enzymes.

\section{A CLOSER LOOK}

How animals are cloned and why problems sometimes occur

Cloning by nuclear transfer is a two-part process. First, scientists remove the nucleus from an egg, and then they fuse it with a somatic cell containing the nucleus and genetic material from another cell by the application of an electrical charge. The fused egg is then placed in a laboratory dish with the appropriate nutrients. Eventually the resulting embryo, which is a genetic copy of the animal that produced the somatic cell and not the egg, is transplanted into a surrogate mother.

The successful production of normal clones from differentiated somatic cells suggests that adult nuclear DNA retains the ability to direct the correct pattern of gene expression for embryogenesis. The process of resetting adult nuclear DNA to the embryonic pattern of gene expression is known as reprogramming and likely involves switching off certain genes and turning on others. Errors in reprogramming may lead to abnormalities in gene expression in cloned animals and affect the health and longevity of the animal.

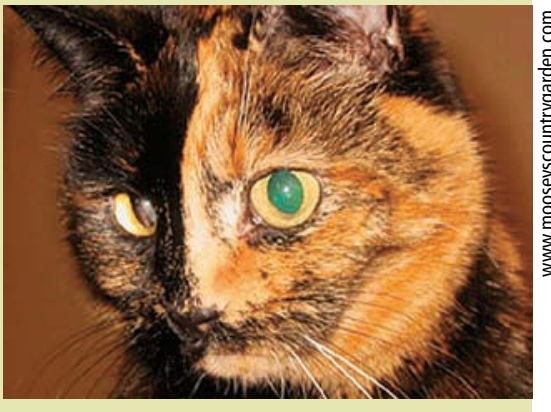

Epigenetic changes are visible in tortoiseshell female cats. Depending upon which X-chromosome becomes inactivated, some skin cells give rise to orange fur while others give rise to black fur.
Reprogramming involves changes at the epigenetic level. Epigenetic changes refer to alterations in gene expression resulting from modifications of the genome that do not include changes in the base sequence of DNA. Two key areas of epigenetic control are chromatin remodeling and DNA methylation. Epigenetic changes may also include imprinting, the switching off of maternal or paternal copies of certain genes.

With clones the reprogramming of somatic cell modifications is sometimes incomplete, leading to inappropriate patterns of DNA methylation, chromatin modification and $\mathbf{X}$-chromosome inactivation in the developing clone. This can result in aberrant gene-expression patterns and correspondingly high rates of pregnancy loss, congenital abnormalities and postnatal mortality.

- A.L. Van Eenennaam 


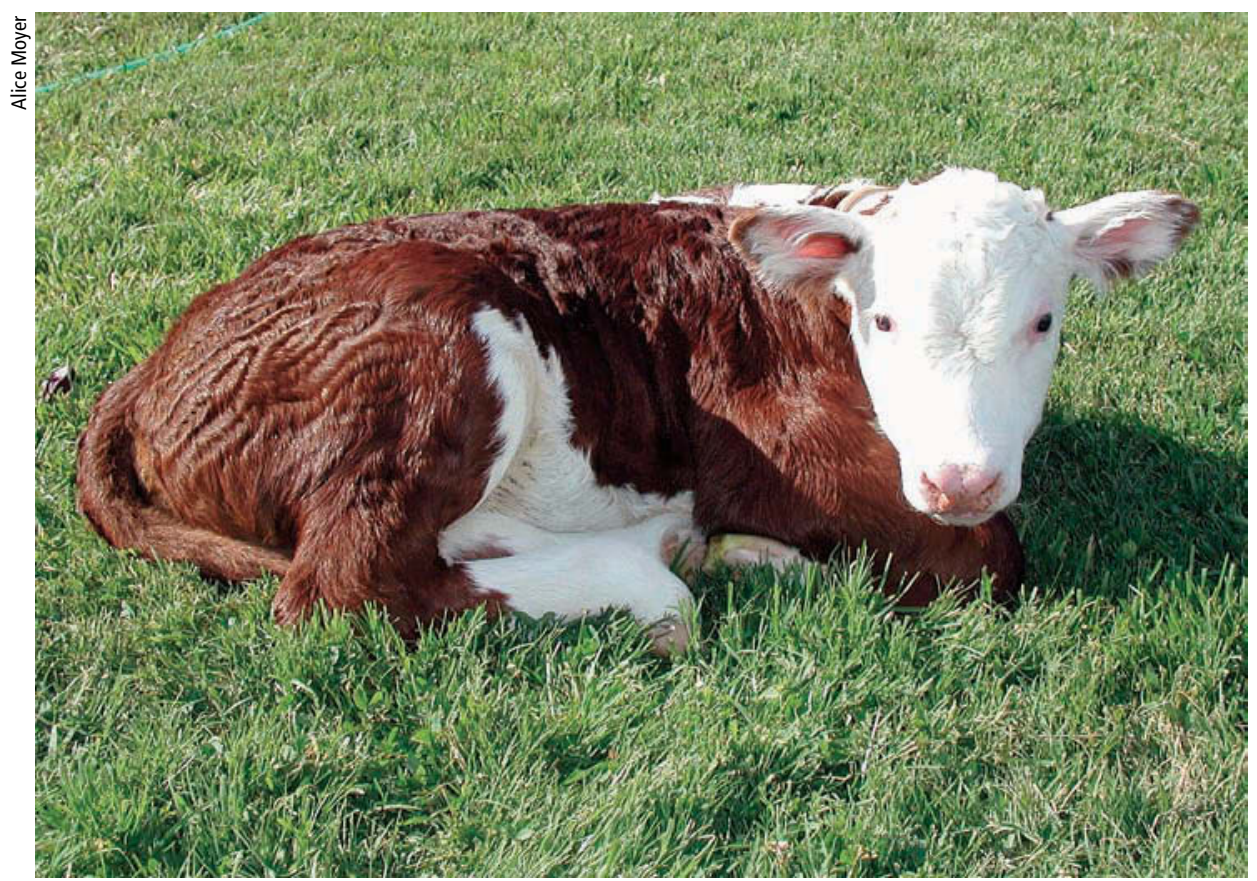

clones, but the term is now more commonly used to refer to an individual that results from the transplantation of the DNA contained in a single somatic (non-egg) cell derived from an adult organism, into an enucleated oocyte (an egg that has had its own DNA removed). This process is called somatic cell nuclear transfer (SCNT) cloning, and it has been successfully performed in many livestock species (e.g., sheep, cattle, pigs and goats). From an animal breeding perspective, the importance of the SCNT procedure is that it allows the replication of adult animals with demonstrated superior performance attributes. Commercial companies providing fee-for-service cattle cloning have recently emerged, offering producers guaranteed-live cloned offspring for $\$ 10,000$ to $\$ 20,000$ per calf.

Agricultural uses. There are probably only a few prospective uses for cloned animals in commercial agricultural operations. They may provide a genetic insurance policy in the case of extremely valuable animals, or produce several identical sires in production environments where artificial insemination is not a feasible option. Theoretically, clones could also be used to reproduce a genotype that is particularly well suited to a given environment. The advantage of this approach is that a genotype that is proven to do especially well in a par- ticular location could be maintained indefinitely, without the genetic shuffle that normally occurs every generation with conventional reproduction.

However, the disadvantage of this approach is that it freezes genetic progress toward desirable attributes, such as milk production or disease resistance, at one point in time. Since there is no genetic variability in a population of clones, within-herd selection no longer offers an opportunity for genetic improvement. Additionally, the lack of genetic variability could render the herd or flock vulnerable to a catastrophic disease outbreak or singularly ill-suited to changes that may occur in the environment.

Although clones carry exactly the same genetic information in their chromosomal DNA, they may still differ from each other, in much the same way that identical twins do not look or behave in exactly the same way. Clones do not share the same cytoplasmic inheritance of mitochondria from the donor egg, nor often the same gestational environment, since they are frequently borne and raised by different animals. In fact, a recent study showed that SCNT clones differ more from each other than do contemporary half-siblings (Lee et al. 2004).

Efficiency and problems. The cloning procedure is currently inefficient, with
Rosie, left, born May 2002, was the first clone to be released from the UC Davis Veterinary Medicine Teaching Hospital. She died unexpectedly of a bacterial septicemia at 2 years of age. While it is unclear why Rosie became ill, there are some reports in the scientific literature of the premature death of cloned cattle.

- Leslie Lyons, right, associate professor in the UC Davis School of Veterinary Medicine, studies cats to investigate the genetic bases for inherited diseases in animals and humans. In 2002, Lyons confirmed that a cat born at Texas A\&M University was the first cloned feline. Kiwi and Kashmir are purebred Oriental shorthair kittens that carry a lympho-sarcoma gene.

$\longrightarrow$ Far right, scientists with UC Davis and Origen Therapeutics of Burlingame, Calif., have developed a system that uses primordial germ cells (PGCs) to pass on introduced traits to the next generation. The black chick among the white rooster's progeny shows that the injected PGCs successfully developed into sperm and that its genotype was passed on.

only $1 \%$ to $3 \%$ of the nucleated egg cells developing into live offspring. High rates of pregnancy loss have been observed at various times after placement of the eggs containing the adult cell nuclei into recipient animals. However, these problems are not seen universally in SCNT-cloned cattle, and there are reports of apparently healthy cloned cattle that have gone on to conceive and have healthy calves (Lanza et al. 2001; Pace et al. 2002).

Abnormalities have also been observed in cloned animals subsequent to birth, with frequencies that are at least partially dependent upon the type of tissue from which the transferred nucleus was derived. These abnormalities include defects in cardiovascular, musculoskeletal and neurological systems, as well as susceptibility to infections and digestive disorders. Many of these problems appear to result from incorrect reprogramming of the transferred nuclear DNA as it transitions from directing the cellular activities of a somatic cell to directing the complex developmental pathway required to develop into an entirely new embryo. Researchers have documented abnormal gene expression patterns in cloned offspring and errors in both imprinting and X-chromosome inactivation (Thibault 2003).

Food safety. The main underlying food-safety concern with SCNT clones is whether the nuclear reprogramming 


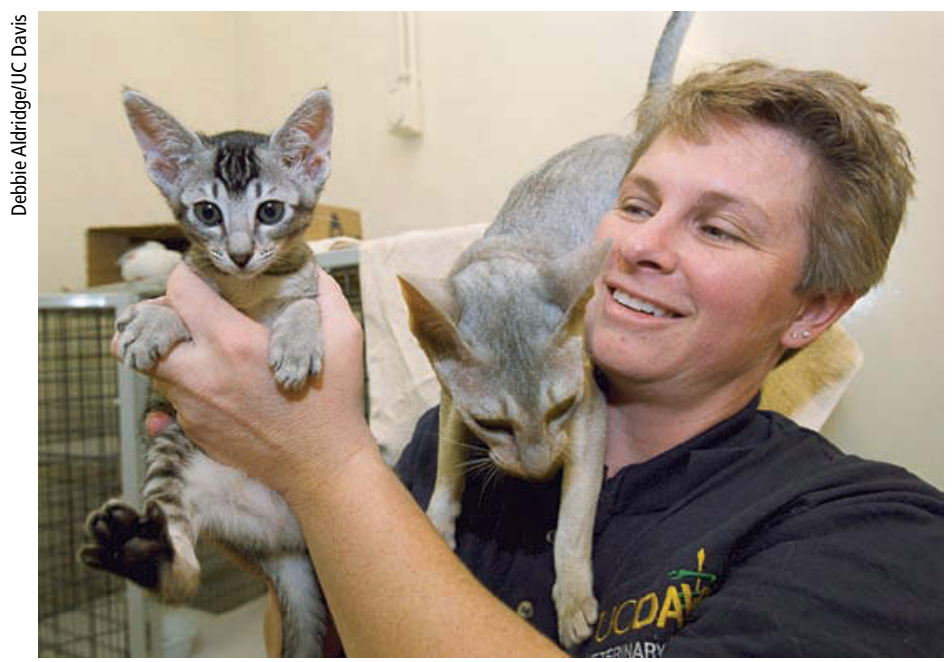

that occurs during the cloning process has any influence on the composition of animal food products. There is no fundamental reason to suspect that animals derived via SCNT would produce novel toxins or allergens. Studies comparing the performance of SCNT clones and other types of dairy cattle clones to their full siblings found that there were no obvious differences in performance or milk composition (Takahashi and Ito 2004; Norman and Walsh 2004; Walsh et al. 2003; Tome et al. 2004; Tian et al. 2005).

The FDA Center for Veterinary Medicine has been developing a risk assessment to identify hazards and characterize food consumption risks that may result from cloning (Rudenko et al. 2004). Their report on livestock cloning states, "the current weight of evidence suggests that there are no biological reasons, either based on underlying scientific assumptions or empirical studies, to indicate that consumption of edible products from clones of cattle, pigs, sheep or goats poses a greater risk than consumption of those products from their nonclone counterparts" (FDA 2003). Despite these findings, the marketing of milk or meat from SCNT clones and their offspring remains subject to a voluntary prohibition. The FDA report states, "additional data on the health status of progeny, and composition of milk and meat from clones and their progeny, would serve to further increase the confidence in these conclusions." Several research groups are actively collecting these types of data.

Pets. Although the cloning of livestock has been ongoing for several years, the first cloned-toorder pet was sold in December 2004. "Little Nicky" was cloned from a deceased 17-year old cat named Nicky and cost its owner $\$ 50,000$. This development fueled a debate over the need for such a product given that millions of cats are euthanized each year for want of homes, and the potential exploitation of grieving pet owners. This led to the introduction of California Assembly Bill 1428 to ban the retail sale of cloned and genetically modified pets. This bill failed to pass in the Assembly Business and Professions Committee in May 2005.

\section{Genetic engineering}

Although cloning is not genetic engineering per se, there is a logical connection between these two technologies. Genetic engineering involves the modification of characteristics of organisms using recombinant DNA techniques, with the specific intent of altering protein expression. A transgenic organism carries DNA originally derived from an organism other than its parents in its genomic DNA. Common examples of transgenic agricultural organisms are insect-resistant corn and cotton that has DNA from the soil microorganism Bacillus thuringiensis (Bt) incorporated into its genome (see page 116). To be passed on to the next generation, this novel transgenic DNA must be pres-

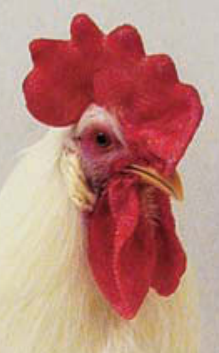

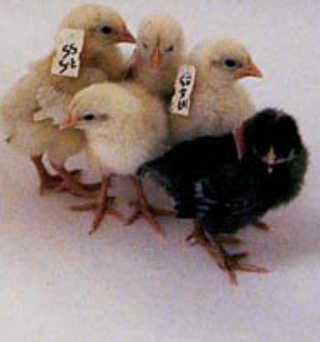

ent in the organism's germ-line cells (egg or sperm). Microinjection of foreign DNA into newly fertilized eggs has been the predominant method used for the generation of transgenic livestock over the past 20 years. This technology is inefficient (3\% to 5\% of animals born carry the transgene) and results in random integration and variable expression levels of the target gene in the transgenic offspring.

Cloning enhances the efficiency of genetic engineering by offering the opportunity to produce $100 \%$ transgenic offspring from cell lines that are known to contain the transgene. This prospect stimulated the research that led to the development of SCNT cloning of animals, despite widespread media coverage about the highly controversial issue of human reproductive cloning. Cloning also offers the unique opportunity to produce animals from cells that have undergone precise, characterized modifications of the genome. This includes the disruption of specific endogenous genes, like those that encode the prion protein responsible for mad cow disease (bovine spongiform encephalopathy), or the allergenic proteins that cause the 


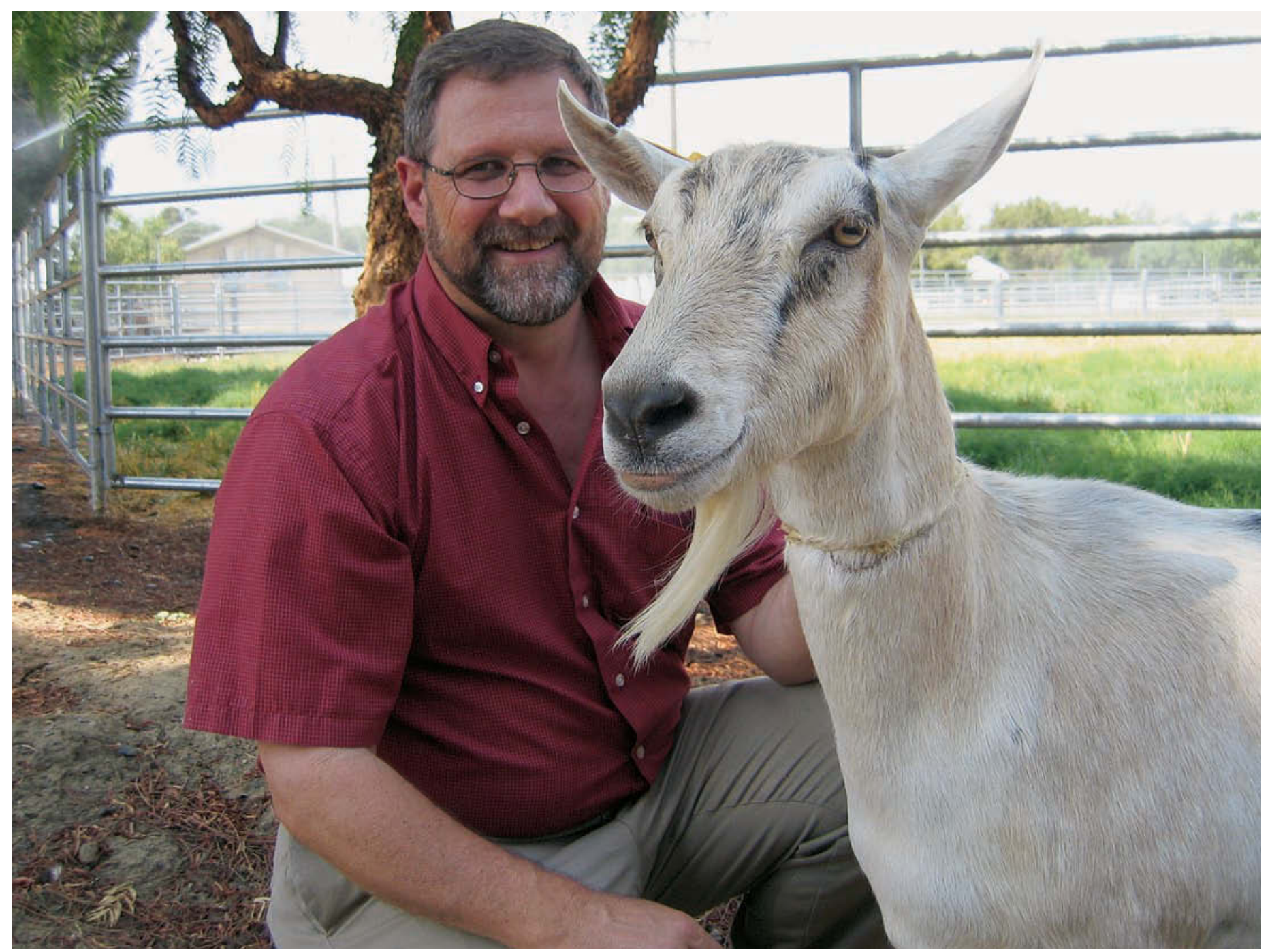

James D. Murray, UC Davis animal science professor, and Artemis, the 7-year-old founder of a transgenic dairy goat herd at UC Davis. The goats express a lysozyme protein found in human breast milk into the udder, where it is secreted into the milk and confers increased antimicrobial activity.

rejection of animal organs in human xenotransplantation surgeries (where animal organs are transplanted into human patients) (Piedrahita and Mir 2004).

Agricultural applications. Genetic engineering was originally envisioned to have a multitude of agricultural applications. Recombinant bovine somatotropin (BST) derived from genetically engineered bacteria is one product of genetic engineering that is currently being used in animal agriculture. This protein, which increases milk production in lactating cows, is widely used throughout the U.S. dairy industry. Administering the protein rBST does not modify the DNA of the cow, and they do not become genetically engineered. BST was approved by the FDA in 1993 following extensive testing by numerous medical associations and scientific societies, which revealed no health or safety concerns for consumers (Bauman 1999).

The FDA is again the lead agency responsible for the regulation of genetically engineered food animals, and it plans to regulate transgenic animals under the new animal drug provisions of the Federal Food, Drug, and Cosmetic Act. To date only one company has publicly announced a request for FDA approval to market a genetically engineered food animal, a salmon that is capable of growing four to six times faster than standard salmon grown under the same conditions (see page 126).

At this point it seems unlikely that genetic engineering will find widespread use for improving most livestock production traits. Agriculturally relevant traits such as growth tend to be controlled by many genes, making it difficult to select or predict how the expression of one or two recombinant proteins might influence these complex performance traits. Additionally, traditional selection techniques achieve reliable and consistent rates of genetic improvement for most livestock species and do not require the investment, risk and time involved for the production and regulatory approval of genetically engineered organisms. Enhancing the nutritional attributes or safety of food animal products in ways that are not possible through traditional selection techniques, such as the production of hypoallergenic milk or low-cholesterol eggs, is one area where the genetic engineering of agricultural animals might provide unique opportunities for value-added products in the future. 


\section{Although clones carry exactly the same genetic information in their chromosomal DNA, they may still differ from each other, in much the same way as identical twins do not look or behave in exactly the same way.}

\section{Pharmaceutical/industrial uses.}

The most cost-effective application of genetic engineering in animals, at least in the short term, is likely to be the production of useful protein products. This involves applying genetic engineering to incorporate DNA sequences that encode desired proteins into the genome of animals. In contrast to the narrow profit margins for agricultural products, pharmaceutical or industrial proteins can be sold at a substantial markup.

Transgenic proteins have been produced and secreted into the milk, blood, urine and semen of livestock, although to date most commercial systems favor the mammary gland.

One company, GTC Biotherapeutics, produces more than 60 different therapeutic proteins in the milk of both goats and cows. One of these proteins is antithrombin, a human plasma protein with anticoagulant and antiinflammatory properties, which was planned for market launch in Europe in mid-2005. However, the Committee for Medicinal Products for Human Use of the European Medicines Agency issued a negative opinion on the Market Authorization Application for this product in March 2006. This decision was not related to the fact that its source was a transgenic animal, but rather to the determination that an insufficient number of surgical patients had been enrolled in a clinical trial to support approval of the product. GTC has exercised its right to have its application reexamined, and expects the reexamination to conclude in mid-2006.

Many human therapeutic proteins require modifications specific to animal cells in order to be effective, and genetically engineered animals could provide an important source of these protein drugs in the future. Another company, Nexia, has successfully produced spider silk proteins in the milk of genetically engineered goats. These proteins are purified from the milk and used to produce BioSteel, a strong fiber with medical, military and industrial applica- tions. Other companies have not been commercially successful. The pioneering company PPL Therapeutics, which was responsible for the cloning of Dolly, experienced financial difficulties that resulted in the eventual sale of the company and its laboratories.

Environmental concerns. A report by the National Academy of Sciences stated that environmental issues were the greatest science-based concern facing the animal biotechnology industry (NRC 2002). The possibility that genetically engineered organisms, particularly fish and insects, could escape confinement and become feral was of high concern. The report also noted that the interbreeding of genetically engineered fish, especially those with increased fitness attributes (e.g., younger age at sexual maturity) could result in serious ecological consequences (Muir and Howard 1999, 2001, 2002).

The actual environmental risk posed by each species/transgene combination will depend upon a number of factors including the containment strategy(s), species mobility, ability to become feral, genotype-by-environmental interactions and stability of the receiving community. Likewise, food safety concerns related to transgenic animals will be similarly case-specific depending upon the attributes of the recombinant protein and whether it is intended to be a pharmaceutical, industrial or food protein. To encourage academic research in this area, the U.S. Department of Agriculture's (USDA) Biotechnology Risk Assessment Grants Program currently provides $\$ 3$ million annually to support research designed to identify and develop appropriate management practices, and to minimize the physical and biological risks associated with genetically engineered animals, plants and microorganisms.

\section{Animal welfare considerations}

Animals are sentient, living creatures, and they are often treasured members of the family. As a result of varying personal belief systems, some people oppose the human use of animals for any purpose, while others have specific concerns about the impacts that genetic engineering and cloning may have on animal health and welfare. Some people find it particularly disturbing that industrial terminology such as "transgenic animal bioreactors" is used to describe genetically engineered animals producing human therapeutic or industrial proteins.

Animal cloning and transgenic methodologies themselves create some welfare concerns, not the least of which is the current inefficiency of the techniques, which results in the use of many more animals than would be needed if success rates were higher. Some of the reproductive manipulations (e.g., embryo transfer, superovulation) that are required for the production of genetically engineered animals and clones may cause pain or discomfort to the animal. However, these are not new or unique concerns specific to these biotechnologies; commercial livestock breeders have commonly employed such techniques for many years.

A problem that is often seen with bovine embryos cultured using in vitro embryo culture techniques (e.g., SCNT clones) is that the resultant calves tend to have high birth weights and long gestational periods. This phenomenon, known as large offspring syndrome, can result in calving difficulties and an increased rate of caesarian section for the dam. An animal welfare concern more specifically associated with genetically engineered animals is poorly controlled expression of the introduced gene. Various growth abnormalities have been noted in genetically engineered animals that are expressing a growth hormone transgene (Pursel et al. 1989; Devlin et al. 1995).

A more overriding concern is related not to the actual genetic manipulations themselves, but rather to animal welfare problems precipitated by breed- 


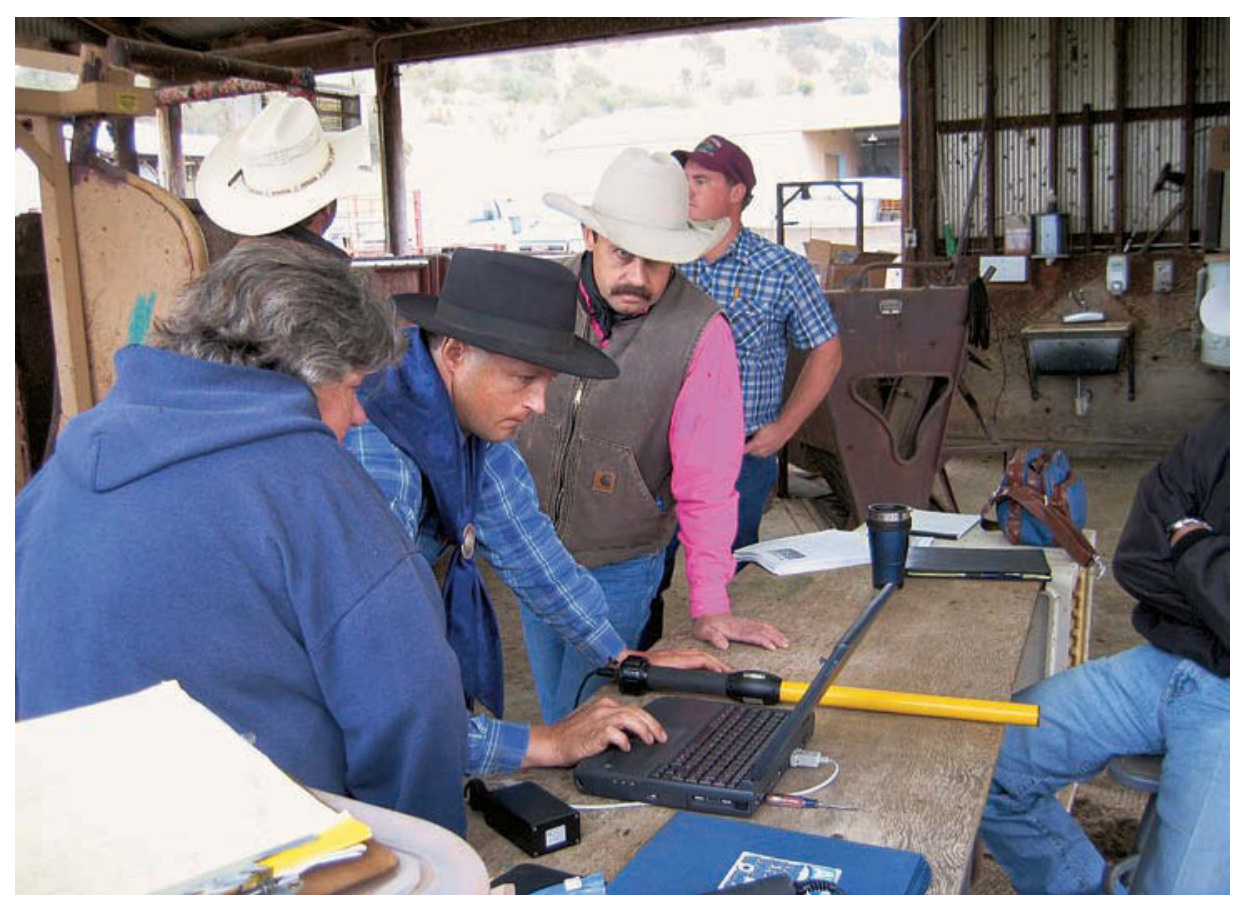

The adoption of modern technologies is becoming increasingly important for the success of commercial livestock operations. Above, researchers at the UC Sierra Foothill Research and Extension Center use DNA tests and electronic animal identification equipment to individually track the parentage and performance of each animal and identify genetically superior breeding stock.

ing objectives. If biotechnology makes farm animal production more efficient, this may have the effect of worsening conditions that some already see as unacceptable, such as those found in concentrated animal-feeding operations.

This concern is again not unique to genetic engineering, because any genetic selection program directed exclusively toward high production efficiency has the potential to cause welfare concerns for farm animals, irrespective of the techniques used to obtain that goal. Conversely, animal biotechnology might also be used to improve traits such as disease resistance, which could have the effect of decreasing animal suffering or mortality.

Although it is possible that genetic engineering will be used to increase agricultural productivity, in the short term it seems more likely that this technique will be used for biomedical applications. In this case, genetic manipulation is not intended to cause changes that have physiologic effects on the animals themselves and generally raises fewer potential animal welfare concerns (NRC 2002). There are still some unique concerns such as the premature lactational shutdown that has been observed in some animals ex- pressing recombinant proteins in their mammary gland (Shamay et al. 1992). Additionally, the specific pathogen-free housing requirements for animals intended to produce human therapeutics or organs for human transplantation may compromise the behavioral needs of the animal.

\section{Ethical concerns}

One genetically engineered animal, a red fluorescent zebrafish called GloFish, is commercially available in the United States (see page 126). Federally, the FDA decided not to regulate GloFish on the basis that tropical fish pose no threat to the food supply and the fact that there is no evidence that these genetically engineered zebrafish pose any greater threat to the environment than their widely sold, unmodified counterparts. However, California's Fish and Game Commission decided to prevent the sale of these transgenic zebrafish to aquarium hobbyists in the state. This decision was not founded on science-based evidence of environmental risk - since zebrafish is a tropical species that is not sufficiently cold tolerant to reproduce in California waters - but rather on ethical grounds. In reaching this decision, one of the commissioners stated that he did not think it was right to produce a new genetically engineered organism "just to be a pet."

This brings up a unique aspect of genetic engineering as it relates to animals, and that is the special place that animals hold in our society. It is doubtful that a genetically modified blue rose would be prohibited based on the fact it was just going to be in a floral arrangement. There are two central ethical concerns associated with the genetic engineering of animals. The first has to do with breaching species barriers or "playing God." Proponents of this view suggest that life should not be regarded solely as if it were a chemical product subject to genetic alteration and patentable for economic benefit. The second major ethical concern is that the genetic engineering of animals interferes with the integrity or "telos" of the animal. Telos is defined as "the set of needs and interests which are genetically based, and environmentally expressed, and which collectively constitute or define the form of life or way of living exhibited by that animal, and whose fulfillment or thwarting matter to that animal" (Holland and Johnson 1998).

Scientists might argue that science does not make value or moral judgments, and therefore ethics is not scientifically relevant. The scientific process places a high value on controlled experiments as a way to obtain understanding. Potential, and maybe even fanciful concerns, do not mesh well with a process that focuses on what can be measured, analyzed and quantified. This proclivity to value that which is verifiable and subject to experimental manipulation may be at odds with the values of other groups in society. Given that ethics are difficult to integrate into the scientific process, it is perhaps not surprising that scientists often fail to articulate the ethical issues occasioned by their work, allowing that discussion to be carried out in the press or by those with a particular axe to grind. To help address this disconnect, graduate students at many universities are now required to attend ethics courses in addition to their core curriculum. 


\section{Public perceptions}

In a survey conducted in 2005 , only $6 \%$ of respondents indicated they had heard or read a lot about applying the science of biotechnology to animals, and $45 \%$ indicated they had heard "nothing at all" about the topic (IFIC 2005). A 2003 public knowledge study by Rutgers University found that $51 \%$ of respondents associated the word "cloning" with the terms "genetic engineering" and "genetic modification," which is perhaps not surprising given that these terms are not used consistently in the media. Despite finding that the majority of people surveyed admitted to knowing "very little" $(55 \%)$ or "nothing at all" $(22 \%)$ about biotechnology, the Rutgers study also found that the majority of those interviewed disapproved of animal-based "genetically modified" foods (Hallman et al. 2003). As a point of reference, half of the respondents in a 2002 study by the same group had never heard about traditional livestock crossbreeding schemes, and this widely used breeding approach received only a $31 \%$ acceptance rating; at the same time, $50 \%$ of the respondents indicated that they considered the crossbreeding of animals to be morally wrong (Schilling et al. 2002).

The Rutgers studies showed that for many Americans, biotechnology remains an abstract and unfamiliar concept that, in the absence of other information or knowledge, evokes negative reactions. Many of the respondents who initially disapproved of the genetic modification of animals in an abstract sense later indicated that they approved when presented with specific examples, suggesting that opinions about genetic modification are malleable when additional information is presented. This is perhaps not surprising given the fact that most people do not consider themselves informed about biotechnology and related topics, and they generally lack knowledge about the process of livestock and food production in the United States (Hallman et al. 2003). Many people change their attitudes when presented with information on why the technology is being used, and if they view the potential benefits as important.

\section{Communicating risks and benefits}

Although to date the only genetically engineered animal available on the U.S. market (but not in California) is a glowing red aquarium fish, this technology has the potential to address other more vital societal interests. Given that the term "animal biotechnology" elicits a negative public reaction in the absence of any other information, scientists have an obligation to engage in the public discourse by articulating the science-based risks and benefits of their research, in addition to the ethical issues occasioned by their work. Polarizing the issue of genetic engineering of animals into "all is permitted" or "nothing is permitted" prevents rational social progress on the issue. Effective and responsible communication among scientific, community, industry and government stakeholders is essential to reach a societal consensus on the acceptable levels of risk for specific products of animal biotechnology, and to determine which set of values will ultimately be applied to decide the acceptable uses of animal biotechnology.

A.L. Van Eenennaam is Animal Genomics and Biotechnology Cooperative Extension Specialist, UC Davis.

\section{References}

Bauman DE. 1999. Bovine somatotropin and lactation: From basic science to commercial application. Domest Anim Endocrinol 17(2-3):101-60.

Dekkers JCM, Hospital F. 2002. The use of molecular genetics in the improvement of agricultural populations. Nat Rev Genet 3(1):22-32.

Devlin RH, Yesaki TY, Donaldson EM, et al. 1995. Transmission and phenotypic effects of an antifreeze $\mathrm{GH}$ gene construct in coho salmon (Oncorhynchus kisutch). Aquaculture 137(1-4):161-9.

[FDA] Food and Drug Administration. 2003. Animal Cloning: A Risk Assessment. DRAFT Executive Summary. 11 p. www.fda.gov/cvm/Documents/CLRAES.pdf.

Hallman WK, Hebden WC, Aquino HL, et al. 2003. Public Perceptions of Genetically Modified Foods: A

National Study of American Knowledge and Opinion. Food Policy Institute, Cook College, Rutgers - The State University of New Jersey. New Brunswick, NJ. 36 p. www.foodpolicyinstitute.org/docs/reports/ NationalStudy2003.pdf

Holland, A, Johnson A. 1998. Animal Biotechnology and Ethics. London: Chapman Hall. 351 p. [IFIC] International Food Information Council. 2005. U.S. Consumer Attitudes Toward Food Bio- technology. 11 p. www.ific.org/research/upload/ 2005BiotechSurvey.pdf.

Lanza RP, Cibelli JB, Faber D, et al. 2001 Cloned cattle can be healthy and normal. Science 294(5548):1893-4.

Lee RSF, Peterson AJ, Donnison MJ, et al. 2004. Cloned cattle fetuses with the same nuclear genetics are more variable than contemporary half-siblings resulting from artificial insemination and exhibit fetal and placental growth deregulation even in the first trimester. Biol Reprod 70(1):1-11.

Muir WM, Howard RD. 1999. Possible ecological risks of transgenic organism release when transgenes affect mating success: Sexual selection and the Trojan gene hypothesis. Proc Natl Acad Sci USA 96(24):13853-6.

Muir WM, Howard RD. 2001. Fitness components and ecological risk of transgenic release: A model using Japanese medaka (Oryzias latipes). Am Nat 158(1):1-16.

Muir WM, Howard RD. 2002. Assessment of possible ecological risks and hazards of transgenic fish with implications for other sexually reproducing organisms. Transgenic Res 11(2):101-14.

Murray JD, Anderson GB. 2000. Genetic engineering and cloning may improve milk, livestock production. Cal Ag 54(4):57-65.

Norman HD, Walsh MK. 2004. Performance of dairy cattle clones and evaluation of their milk composition. Cloning Stem Cells 6(2):157-64.

[NRC] National Research Council. 2002. Animal Biotechnology: Science-based Concerns. Washington, DC: Nat Acad Pr. 181 p.

Pace MM, Augenstein ML, Betthauser JM, et al. 2002. Ontogeny of cloned cattle to lactation. Biol Reprod 67(1):334-9.

Piedrahita JA, Mir B. 2004. Cloning and transgenesis in mammals: Implications for xenotransplantation. Am J Transplant 4:43-50.

Pursel VG, Pinkert CA, Miller KF, et al.1989. Genetic-engineering of livestock. Science 244(4910):1281-8.

Rudenko L, Matheson JC, Adams AL, et al. 2004 Food consumption risks associated with animal clones: What should be investigated? Cloning Stem Cells 6(2):79-93.

Schilling BJ, Hallman WK, Adelaja AO, Marxen LJ. 2002. Consumer Knowledge of Food Biotechnology: A Descriptive Study of U. S. Residents. Food Policy Institute, Cook College, Rutgers - The State University of New Jersey. 25 p. www.foodpolicyinstitute.org.

Shamay A, Pursel VG, Wilkinson E, et al. 1992. Expression of the whey acidic protein in transgenic pigs impairs mammary development. Transgenic Res 1(3):124-32.

Takahashi S, Ito Y. 2004. Evaluation of meat products from cloned cattle: Biological and biochemical properties. Cloning Stem Cells 6(2):165-71.

Thibault C. 2003. Recent data on the development of cloned embryos derived from reconstructed eggs with adult cells. Reprod Nutr Dev 43(4):303-24.

Tian XC, Kubota C, Sakashita K, et al. 2005. Meat and milk compositions of bovine clones. Proc Natl Acad Sci USA 102(18):6261-6.

Tome D, Dubarry M, Fromentin G. 2004. Nutritional value of milk and meat products derived from cloning. Cloning Stem Cells 6(2):172-7.

Walsh MK, Lucey JA, Govindasamy-Lucey S, et al. 2003. Comparison of milk produced by cows cloned by nuclear transfer with milk from non-cloned cows. Cloning Stem Cells 5(3):213-9. 